\title{
Morphometric analysis of thyroid cell aspirates
}

\author{
R G WRIGHT, ${ }^{*}$ H CASTLES, $\dagger$ R H MORTIMER $\dagger$ \\ From the * Queensland Cytology Service, North Brisbane Hospitals Board, and the †Department of \\ Endocrinology, Royal Brisbane Hospital, Brisbane, Queensland, Australia
}

SUMMARY One hundred and nineteen patients with thyroid nodules underwent fine needle aspiration cytology. Fifty eight were subsequently shown to have multinodular goitre: 36 had a follicular adenoma; 12 follicular carcinoma; and 13 papillary carcinoma on paraffin section. Morphometry performed on the aspirated cells stained by Papanicolaou and Giemsa methods showed significant differences in mean nuclear area and nuclear perimeter between groups of patients with benign thyroid nodules and those with malignant nodules. The wide variation in the mean nuclear areas and perimeters, however, severely limits the diagnostic use of morphometry in individual aspirates.

Fine needle aspiration cytology has been widely used in the assessment of thyroid nodules. Many investigators have shown that the technique is valuable, ${ }^{1-5}$ but others have emphasised limitations and urged caution. ${ }^{6}$ Although false positive results are rare, the usefulness of the technique has been limited to some extent by difficulties in distinguishing follicular adenomas and multinodular goitres from well differentiated follicular carcinoma and papillary carcinoma of the thyroid. Even in centres where large numbers of aspirates have been processed over many years, ${ }^{78}$ histologically incorrect diagnosis of malignancy occurs in up to $25 \%$ of cases.

Computed morphometric methods have been introduced to try to improve the diagnostic yield from fine needle aspirates of the thyroid. Some authors have found this to be useful, ${ }^{9-11}$ but others have not. ${ }^{1213}$ These published series used Giemsa stained preparations. As most cytopathologists are familiar with Papanicolaou stained preparations, we present the results of morphometric analysis of both Giemsa and Papanicolaou stained preparations of aspirated cells from thyroid nodules of patients subsequently shown by histology to have multinodular goitre, follicular adenoma, follicular carcinoma, or papillary carcinoma.

\section{Material and methods}

\section{STUDY POPULATION}

One hundred and nineteen patients with thyroid nodules were studied. These included 29 men (mean age 44.9 years) and 90 women (mean age 43.7 years).

Accepted for publication 21 October 1986
Aspirates were performed using a 23 gauge needle. The smears were immediately fixed in $95 \%$ ethanol and stained using a standard Papanicolaou method. ${ }^{14}$ In addition, smears from 49 patients were air dried and stained using a commercial variation of Wright's Giemsa stain (Diff-Quik Solution 1, Lab Aids, Narrabeen, New South Wales, Australia).

\section{MOR PHOMETRIC ASSESSMENT}

The smears were evaluated and reported in the usual manner using diagnostic criteria outlined by Miller et al. ${ }^{15}$ In addition, morphometry was carried out using the MOP-Videoplan image analysis system (Zeiss, Oberkochen, West Germany). At least 25 randomly selected thyroid cells were selected for diagnosis cell groupings on each slide. All had intact nuclei. The figure of 25 was chosen on the basis of preliminary studies and the results published by Luck et al. ${ }^{12}$ The nuclei were displayed on a graphics tablet and outlined manually using a cursor at a magnification factor of 400 . Nuclear area and perimeter were then computed and data stored. Attempts were made to estimate whole cell area and perimeter so that cytoplasmic area and nucleus:cytoplasm ratio could be calculated. It was difficult, however, to identify precisely the thyroid cell boundaries (fig 1).

Calibration was checked regularly by using a slide micrometer. Reliability was confirmed by repeated measurements of a control group of aspirates randomly interspersed among the study samples. Measurements were carried out by a single observer (HC), who had no knowledge of the results of cytological assessment of the aspirates or the histological diagnosis. 


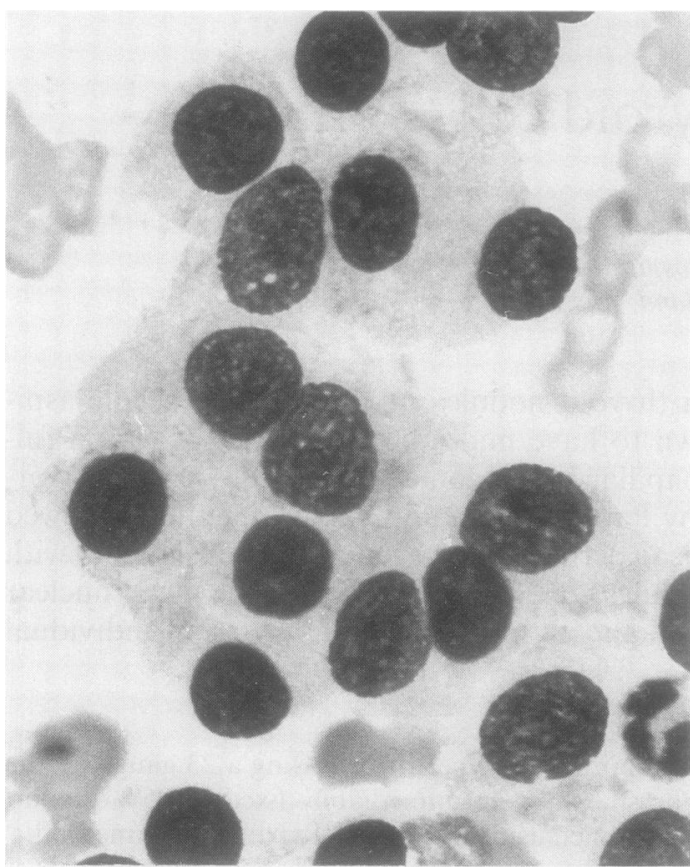

Fig 1 Fine needle aspiration from thyroid nodule of patient subsequently shown to have multinodular goitre. Cytoplasmic boundaries cannot be identified. (Giemsa stain) $\times 960$.

HISTOLOGICAL ASSESSMENT

Histological classification of the subsequent surgical resection specimens was carried out using the WHO classification ${ }^{16}$ by a single observer (RGW), who was not aware of the results of the morphometric analysis of the thyroid aspirates.

\section{STATISTICAL ANALYSIS}

A single factor analysis of variance test was performed using the Newman-Keuls multiple range

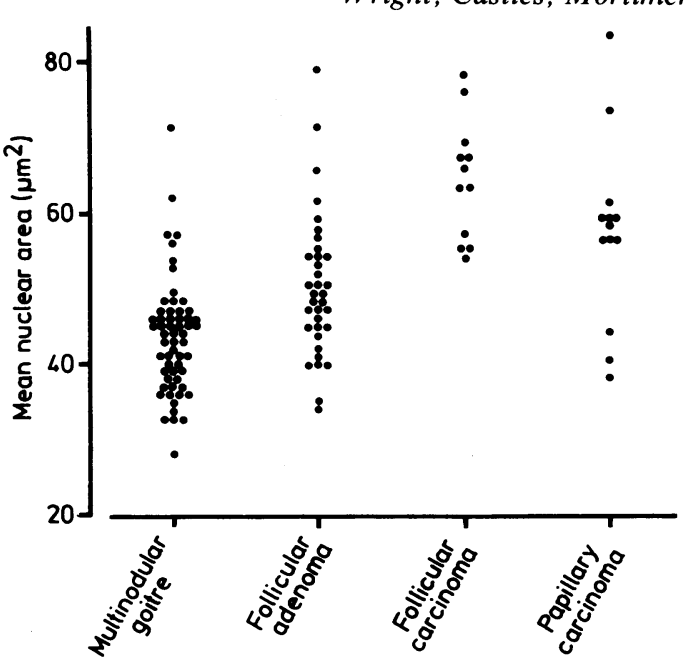

Fig 2 Scattergram showing mean nuclear area of Papanicolaou stained aspirated thyroid cells from 58 patients with multinodular goitre, 36 patients with follicular adenoma 12 patients with follicular carcinoma, and 13 with papillary carcinoma. Diagnoses were established by histological examination of specimens at subsequent thyroid resection.

test ${ }^{17}$ for significance in difference in means between all groups.

\section{Results}

The table shows the distribution of histological diagnoses in the 119 subjects studied. Giemsa stained cytological preparations were available from 20 patients with multinodular goitre, 20 with follicular adenoma, six with follicular carcinoma, and three with papillary carcinoma. Mean nuclear areas and perimeters of aspirated thyroid cells using both Papanicolaou and Giemsa stains are also shown. The mean nuclear areas and perimeters of cells from follicular and papillary carcinomas were significantly larger

Table Nuckar measurements of Papanicolaou and Giemsa stained thyroid aspirates grouped by subsequent histological diagnosis

\begin{tabular}{|c|c|c|c|c|c|c|}
\hline \multirow[b]{3}{*}{ Histological diagnosis } & \multicolumn{6}{|c|}{ Stain } \\
\hline & \multicolumn{3}{|c|}{ Papanicolaou } & \multicolumn{3}{|c|}{ Giemsa } \\
\hline & No & $\begin{array}{l}\text { Nuclear area }\left(\mu m^{2}\right) \\
\text { Mean }( \pm S D)\end{array}$ & $\begin{array}{l}\text { Perimeter }(\mu \mathrm{m}) \\
\text { Mean }( \pm S D)\end{array}$ & No & $\begin{array}{l}\text { Nuclear area }\left(\mu m^{2}\right) \\
\text { Mean }( \pm S D)\end{array}$ & $\begin{array}{l}\text { Perimeter }(\mu m) \\
\text { Mean }( \pm S D)\end{array}$ \\
\hline Multinodular goitre & 58 & $43 \cdot 6(7 \cdot 6)$ & $24 \cdot 2(2 \cdot 1)$ & 20 & $56 \cdot 1(10 \cdot 7)$ & $27 \cdot 7(2 \cdot 4)$ \\
\hline Follicular adenoma & 36 & $50 \cdot 1(9 \cdot 3)$ & $26 \cdot 1(2 \cdot 4)$ & 20 & $66 \cdot 4(14 \cdot 6)$ & $30 \cdot 2(3 \cdot 1)$ \\
\hline Follicular carcinoma & 12 & $64 \cdot 2(8 \cdot 0)$ & $29 \cdot 2(1 \cdot 9)$ & 6 & $84.0(16.9)$ & $33 \cdot 8(3 \cdot 5)$ \\
\hline Papillary carcinoma & 13 & $57 \cdot 1(12 \cdot 2)$ & $27 \cdot 8(3 \cdot 1)$ & 3 & $97 \cdot 4(28 \cdot 2)$ & $36 \cdot 4(5 \cdot 5)$ \\
\hline \multicolumn{7}{|c|}{$\begin{array}{l}\text { The groups are significantly different (Papanicolaou } \mathrm{F}=20.14, \mathrm{p}<0.001 ; \text { Giemsa } \mathrm{F}=10.93, \mathrm{p}<0.001 \text { ). } \\
\text { Papanicolaou: } 4 v 1, \mathrm{p}<0.001 ; 4 v 2, \mathrm{p}<0.02 ; 3 v 1, \mathrm{p}<0.001 ; 3 v 2, \mathrm{p}<0.001 ; 2 v 1, \mathrm{p}<0.001 \text {. } \\
\text { Giemsa: } 4 v 1, \mathrm{p}<0.001 ; 4 v 2, \mathrm{p}<0.005 ; 3 v 1, \mathrm{p}<0.001 ; 3 v 2, \mathrm{p}<0.025 ; 2 v 1, \mathrm{p}<0.05\end{array}$} \\
\hline
\end{tabular}


than those from follicular adenomas and multinodular goitre, and the mean areas and perimeters of follicular adenoma nuclei were significantly larger than nuclei from multinodular goitres. Despite these clear cut and significant differences between means there was a wide scatter of results within each diagnostic category (fig 2 ). Thus in any one patient measurement of nuclear area and perimeter was not helpful in diagnosis.

\section{Discussion}

The results showed significant differences in mean nuclear areas and nuclear perimeters between multinodular goitres and follicular and papillary neoplasms and significant differences between follicular adenomas and follicular and papillary carcinomas. Similar results were found both with air dried Giemsa stained preparations and Papanicolaou stained smears fixed in alcohol.

Clearly delineated cytoplasmic outlines were not obtained with either of our staining procedures, and consequently whole cell areas and derived nucleus: cytoplasmic ratios were not available. Similar difficulties in delineation of cell margins were noted by Luck et al. ${ }^{12}$ Other workers ${ }^{10}$ have been able to measure cell areas. Examination of their published figures suggests, however, that considerable subjective interpretation was required in delineating cytoplasmic margins.

In the present study the mean nuclear areas and perimeters of cells aspirated from malignancies and stained by the Giemsa technique fell between those reported previously. ${ }^{10} 12$

We have found, as have others, ${ }^{1012}$ a wide variation in nuclear measurements from individual thyroid aspirates, and interpretation of nuclear measurements is difficult because of the wide overlap of individual mean values. Therefore, while groups of patients can be adequately separated statistically, we believe that morphometric assessment alone is inadequate to predict malignancy in thyroid aspirates.

This study was financially supported by the Queensland Cancer Fund.
References

I Suen KC, Quenville NF. Fine needle aspiration of the thyroid gland: a study of 304 cases. J Clin Pathol 1983;36:1036-45.

2 Ackerman M, Tennvall J, Biorklund A, Martensson H, Moller T. Sensitivity and specificity of fine needle aspiration cytology in the diagnosis of tumours of the thyroid gland. Acta Cytol 1985;29:850-5.

3 Brauer RJ, Silver CE. Needle aspiration biopsy of thyroid nodules. Laryngoscope 1984;94:38-42.

4 Frable WJ, Frable MA. Thin needle aspiration biopsy of the thyroid gland. Laryngoscope 1980;90:1618-25.

5 Miller JM, Hamburger JI, Kini SR. The needle biopsy diagnosis of papillary thyroid carcinoma. Cancer 1981;49:989-93.

6 Hajdu SI, Melamed MR. Limitations of aspiration cytology in the diagnosis of primary neoplasms. Acta Cytol 1984;28:337-44.

7 Lowhagen T, Granberg P-O, Lindell G, et al. Aspiration biopsy cytology in nodules of the thyroid gland suspected to be malignant. Surg Clinics North America 1979;59:3-18.

8 Walfish PG, Harzani E, Strawbridge HTG, et al. A prospective study of combined ultra-sonography and needle aspiration biopsy in the assessment of the hypofunctioning thyroid nodule. Surgery 1977;82:474-82.

9 Boon ME, Lowhagen T, Willems J-S. Planimetric studies on fine needle aspirates from follicular adenomas and follicular carcinomas of the thyroid. Acta Cytol 1980;24:145-8.

10 Boon ME, Lowhagen T, Cardozo PL, Blonk DI, Kurver PJH, Baak JPA. Computation of preoperative diagnosis probability for follicular adenoma and carcinoma of the thyroid on aspiration smears. Anal Quant Cytol 1982;1:1-5.

11 Boon ME, Bak JPA, Thyroid: morphometry for the preoperative diagnosis: of follicular adenoma and carcinoma. In: A manual of morphometry in diagnostic pathology. Berlin: Springer-Verlag, 1983:76-7.

12 Luck JB, Mumaw VR, Frable WJ. Fine needle aspiration biopsy of the thyroid-differential diagnosis by video image analysis. Acta Cytol 1982;26:793-6.

13 Bondeson L, Bondeson AG, Lindholm K, Ljungberg O, Tibblin S. Morphometric studies on nuclei in smears of fine needle aspirates from oxyphilic tumours of the thyroid. Acta Cytol 1983;4:437-40.

14 Bourne LD. Exfoliative cytology. In: Bancroft JD, Stevens A, eds. Theory and practice of histological techniques, London: Churchill-Livingstone, 1982:428-57.

15 Miller JM, Kini SR, Hamburger JI. Needle biopsy of the thyroid. New York: Praeger, 1983.

16 Hedinger Chr. Histological typing of thyroid tumours. International histological classification of tumours. No 11. Geneva: World Health Organisation, 1974.

$17 \mathrm{Zar}$ JH, Multiple comparisons. In: Biostatistical analysis. New Jersey: Prentice-Hall, 1974:151-4.

Requests for reprints to: Dr RG Wright, Queensland Cytology Service, Department of Pathology, North Brisbane Hospital Board, Herston, Brisbane, Queensland, Australia 4029. 